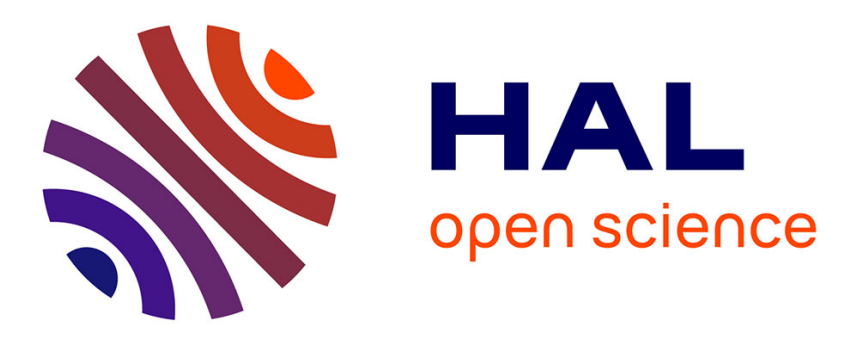

\title{
Power density and temperature effects on the photoluminescence spectra of InAlAs/GaAlAs quantum dots
}

\author{
A. Ben Daly, H. Riahi, Frédéric Bernardot, Thierry Barisien, E. Galopin, A. \\ Lemaitre, M.A. Maaref, Christophe Testelin
}

\section{To cite this version:}

A. Ben Daly, H. Riahi, Frédéric Bernardot, Thierry Barisien, E. Galopin, et al.. Power density and temperature effects on the photoluminescence spectra of InAlAs/GaAlAs quantum dots. Superlattices and Microstructures, 2017, 104, pp.321-330. 10.1016/j.spmi.2017.02.043 . hal-01492785

\section{HAL Id: hal-01492785 \\ https://hal.sorbonne-universite.fr/hal-01492785}

Submitted on 20 Mar 2017

HAL is a multi-disciplinary open access archive for the deposit and dissemination of scientific research documents, whether they are published or not. The documents may come from teaching and research institutions in France or abroad, or from public or private research centers.
L'archive ouverte pluridisciplinaire HAL, est destinée au dépôt et à la diffusion de documents scientifiques de niveau recherche, publiés ou non, émanant des établissements d'enseignement et de recherche français ou étrangers, des laboratoires publics ou privés. 
Power density and temperature effects on the photoluminescence spectra of InAIAs/GaAIAs quantum dots

\author{
A. Ben Daly, ${ }^{1 *}$ H. Riahi, ${ }^{1}$ F. Bernardot,${ }^{2,3 *}$ T. Barisien,,${ }^{2,3^{*}}$, E. Galopin, ${ }^{4}$ A. Lemaître, ${ }^{4}$ M. A. \\ Maaref ${ }^{1}$ and C. Testelin ${ }^{2,3^{*}}$
}

1 Laboratoire Matériaux, Molécules et Applications, Institut Préparatoire aux Études Scientifiques et Techniques, BP 51, 2070 La Marsa, Université de Carthage, Tunis, Tunisia

${ }^{2}$ Sorbonne Universités, UPMC Université Paris 06, UMR 7588, Institut des NanoSciences de Paris, F-75005 Paris, France

${ }^{3}$ CNRS, UMR 7588, INSP, F-75005 Paris, France

${ }^{4}$ Laboratoire de Photonique et Nanostructures, CNRS, UPR 20, Route de Nozay, F-91460 Marcoussis, France

\begin{abstract}
Photoluminescence (PL) and time-resolved photoluminescence (TRPL) measurement techniques are used to characterize the size and the density of $\operatorname{In}_{1-x} \mathrm{Al}_{\mathrm{x}} \mathrm{As} / \mathrm{Ga}_{0.67} \mathrm{Al}_{0.33} \mathrm{As}$ quantum dots (QDs) for different QD aluminium compositions. The integrated photoluminescence intensity (IPL) depends on an excitation light power, decreases with increasing the aluminium proportion emphasizing the QDs surface density decreasing. In TRPL experiments, the influence of QD lateral coupling is evidence in high QD density sample, the radiative lifetime increases with increasing temperatures for sample with a low aluminium proportion, instead, the observed radiative lifetime keep constant for samples with a high aluminium proportions in agreement with the QD zero-dimensional confinement.
\end{abstract}

Keywords:

Quantum dots; photoluminescence; time-resolved photoluminescence; excitation density

*Corresponding author. Tel: +216 23642 756; fax: +216 71746551

E-mail address: amenibendaly@gmail.com 


\section{Introduction}

Charge carriers can be confined in more than one dimension, if different semiconductor heterostructures are grown. If the dimension is smaller than the deBroglie wavelength in two directions, the resulting object is called a nanowire. When charge carriers are confined in all three dimensions, the structure was originally called quantum box and is nowadays called a quantum dot (QD).

The unique properties of quantum dots (QDs) in terms of carrier confinement and delta function like density of states are very appealing for a large number of applications. Improvements of existing devices are possible as well as the realization of completely new designs.

The discrete energy levels lead to a significantly lower threshold current density in laser diodes, which in turn results in reduced power consumption and an increase in the dynamic response essential for direct modulation [1]. Optical memories based on QDs, for example, promise to yield ultra-high density storage media [2]. Another concept that uses large spread of optical transitions is a QD spectrometer proposed by Jimenez et al [3]. The spin states of coupled single-electron QDs can be used for quantum computation [4-6]. Due to the discrete nature of the QD levels, carrier dynamics in QD structures are considerably more complex than in bulk materials. One of the most important experimental tools to study carrier dynamics in QD structures is photoluminescence (PL). Carriers are either excited nonresonantly into the barrier (from the valence band of the bulk material into the conduction band) or resonantly in the QDs (from a valence band QD level to a conduction band level). Under nonresonant excitation conditions, electrons and holes, are created throughout a certain volume determined by focal spot diameter and absorption length, need to be transported to the QD layer before they can be captured. After being captured and confined to QDs, the carriers, which are typically in higher energy states, will start to relax and recombine. It has been long debated, and still not completely qualified, whether the capture and escape of the carriers in QDs occur via single carrier [7-9].

This work will focus on self-assembled InAlAs QDs, produced by Stranski-Krastanov growth either in molecular-beam epitaxy (MBE). In the critical step of this procedure, ${\operatorname{~}{ }_{1-x}}_{A} \mathrm{l}_{\mathrm{x}} \mathrm{As}$ is grown on $\mathrm{Al}_{0.67} \mathrm{Ga}_{0.33} \mathrm{As}$ in a thin layer. As InAlAs and AlGaAs have a lattice mismatch, this leads to a highly stressed surface. Afterwards, these QDs are overgrown with another layer of GaAlAs, the sizes and shapes of the QDs are distributed. Their emission spectrum is broadened by their different sizes and compositions, and only a part of the QD ensemble is able to participate in the lasing process [10-12]. 
In these structures, the increases of excitation power density modify the electronic properties and fill the excited state, involving exciton-exciton interactions. Despite the large experimental and theoretical effort devoted to clarify the carrier thermodynamics in QDs, a few aspects still need a better understanding.

There have not been many studies of the excitation dependence on aluminium concentration. In the following, we present energy emission, full width at half maximum (FWHM) and integrated PL intensity (IPL) of such samples using variable temperature and excitation power density.

\section{Material and methods}

The QD samples of the present study were prepared by molecular-beam epitaxy, and is similar to previously samples $[13,14]$ : the growths of the $\operatorname{In}_{1-x} \mathrm{Al}_{\mathrm{x}} \mathrm{As}$ were performed on a $100 \mathrm{~nm}$-thick $\mathrm{Ga}_{0.67} \mathrm{Al}_{0.33}$ As epilayer, and were monitoring by reflection high-energy electron diffraction (RHEED). The QDs were covered by a $\mathrm{Ga}_{0.67} \mathrm{Al}_{0.33} \mathrm{As}$ epilayer of same composition and same thickness.

Fig. 1 presents a sketch of the sample structure: it contains a single plane of QDs. Table I summarizes the growth characteristics of the studied samples. The aluminium proportion $\mathrm{x}$ in the deposited $\operatorname{In}_{1-\mathrm{x}} \mathrm{Al}_{\mathrm{x}} \mathrm{As}$ alloy ranges from 0.20 to 0.38 (nominal values). The growth temperature is around $550{ }^{\circ} \mathrm{C}$ for all samples. The growth rate is different from sample to sample, and ranges from 0.92 monolayer per second (ML/s) to $1.77 \mathrm{ML} / \mathrm{s}$. The critical thickness, at which the growth turns from two-dimensional (deposition of $\operatorname{In}_{1-\mathrm{x}} \mathrm{Al}_{\mathrm{X}} \mathrm{As}$ layers) to three-dimensional (appearance of $\operatorname{In}_{1-\mathrm{x}} \mathrm{Al}_{\mathrm{x}} \mathrm{As}$ QDs), is detected on the RHEED pattern and measured during the growth process. For each sample, the total amount of deposited $\operatorname{In}_{1-}$ ${ }_{\mathrm{x}} \mathrm{Al}_{\mathrm{x}} \mathrm{As}$ alloy is measured as an equivalent thickness.

Fig. 2 shows the critical thickness as a function of the aluminium proportion $\mathrm{x}$; the symbols are the experimental data, and the continuous line is only a guide for the eyes. The increasing behaviour observed in Fig. 2 is quantitatively consistent with other growths depositing $\operatorname{In}_{1 \text { - }}$ ${ }_{x} \mathrm{Al}_{\mathrm{x}} \mathrm{As}$ on $\mathrm{Ga}_{0.65} \mathrm{Al}_{0.35} \mathrm{As}$ [15] or on $\mathrm{AlAs}$ [16], in spite of the different temperatures of deposition used here; this can be understood by the fact that the critical thickness appears to be independent of growth temperature at high growth rates [15]. 


\section{Results and Discussion}

A first overview of the three samples of Table $\mathrm{I}$ is the following. Sample A has the lowest aluminium proportion (nominal $\mathrm{x}=0.20$ ); the deposited $\mathrm{In}_{1-\mathrm{x}} \mathrm{Al}_{\mathrm{x}} \mathrm{As}$ amount is only $0.7 \mathrm{ML}$ above the critical thickness of 2.7 ML. Sample B has aluminium proportion $x=0.29$, with critical thickness and deposited $\operatorname{In}_{1-\mathrm{x}} \mathrm{Al}_{\mathrm{X}} \mathrm{As}$ amount very similar to the ones of the preceding sample. Finally, sample $\mathrm{C}$ has the highest nominal $\mathrm{x}=0.38$; its critical thickness turns out to be $3.7 \mathrm{ML}$, and the deposited $\mathrm{In}_{1-\mathrm{x}} \mathrm{Al}_{\mathrm{x}} \mathrm{As}$ (large) amount is $2.7 \mathrm{ML}$ above it. The PL measurements were performed in a variable-temperature (10-250K) closed cycle He cryostat and excited by a laser beam at $532 \mathrm{~nm}$ focused on the sample in a $100 \mu \mathrm{m}$ diameter spot. The PL signals are recorded by a silicon avalanche photodiode.

In order to have deeper insight into the optical properties of our QDs, the ground state emission energy of the QD structure as a function of temperature is studied in Fig. 3. The same behavior have been observed for $x=0.20$ (Fig. 3 (a)), $x=0.29$ (Fig. 3 (b)), $x=0.38$ (Fig. 3 (c)), a monotonous redshift of the PL peak position was observed with increasing temperature [17]. The photogenerated carriers in the barrier material are captured by the QDs states prior to their recombination. The captured carriers are localized in the QDs states at low temperature. However, as the temperature increases, the carriers can be thermally activated from shallow states to a mediator channel before being recaptured by the deeper states (larger QDs) [18]. The temperature dependence can be well reproduced by the following BoseEinstein [19] equation:

$$
E_{g}(T)=E_{g}(0)-\frac{\lambda}{\exp \left(\frac{\hbar \omega}{k_{B} T}\right)-1}
$$

Where $E_{g}(0)$ is the band gap at $0 \mathrm{~K}, \lambda$ is the constant of the electron-phonon coupling strength, and $\hbar \omega_{p h}$ refers to the phonon energy. Estimating $\hbar \omega_{p h}$ to be $13.7 \pm 1.5 \mathrm{meV}$, $16.3 \pm 0.6 \mathrm{meV}$ and $4.7 \pm 0.7 \mathrm{meV}$ respectively for $\mathrm{x}=0.20,0.29$ and 0.38 . Phonon energies values corresponding to transverse acoustic mode (TA) in the dot and are associated with one InAs and one AlAs TA(L) energies [20].

Fig. 4 shows full width at half maximum (FWHM) obtained at different temperatures for the different aluminium proportions. The FWHM can be attributed in part to the finite intrinsic emission linewidth of each single QD, which produces a collective emission background. The 
graph shows clearly that the FWHM decreases at low temperature, then increases at higher temperature for $\mathrm{x}=0.20,0.29$ and 0.38 .

This behavior has been previously observed for InAs and InGaAs QDs [21-24]. At low temperature $(\mathrm{T}=10 \mathrm{~K})$, the thermal escape of the carriers from the QDs into the WL cannot occur, because the radiative rate in the QDs is large as compared to the thermal activation rate. So, after a random carrier capture in the QDs, the electron-hole pairs recombine and the PL spectrum is directly related to the QDs emission energy distribution, caused by size fluctuations. When the temperature increases, the carriers in the smallest QDs (and in the confined states with the lowest confinement energies) are thermally activated into the WL or barrier states, where they recombine or are captured by QDs with larger confinement energies. This leads to a decrease of the emission by small QDs, to a narrowing of the PL spectra on the high-energy side, and to a reduction of the FWHM. At high temperatures (above $60 \mathrm{~K}, 80 \mathrm{~K}$ and $100 \mathrm{~K}$ respectively for $\mathrm{x}=0.20,0.29$ and 0.38 ), most of the QDs are concerned by the thermal activation: the excitons are again redistributed among the QDs, hence the PL spectra tend to the QD emission distribution, and the FWHM increases, as observed.

The optical excitation of self-assembled QD systems yields bright luminescence and generally, reveals a Gaussian line shape distribution. Fig. 5 a, b and c show the lowtemperature $(\mathrm{T}=10 \mathrm{~K})$ pump density-dependent PL spectra of samples $\mathrm{A}(\mathrm{x}=0.20), \mathrm{B}(\mathrm{x}=0.29)$ and $\mathrm{C}(\mathrm{x}=0.38)$ respectively.

For sample $\mathrm{B}(\mathrm{x}=0.29)$, it can be observed a single peak above $0.15 \mathrm{~W}$, indicating carrier confined in QDs. When the excitation power is further increased for $0.18 \mathrm{~W}$ to $0.35 \mathrm{~W}$, the intensity of the QD PL-peak decreases, accompanied by an increase in the intensity of the PL peak of the WL as shown in Fig. 5(b). The increase in PL from the WL and the subsequent decrease in PL from QDs indicate carrier re-emission out the QDs, followed by carrier diffusion and finally capture into WL. For sample $\mathrm{C}(\mathrm{x}=0.38)$ (Fig. 5 (c)), one peak is present.

PL displays a red shift with increasing excitation arises from the thermionic emission and a saturation above $6.68 \mathrm{~W} / \mathrm{cm}^{2}$ proved the low luminescence emitting for bigger QDs. Heitz et al. observed a similar behavior for the InAs/GaAs QDs [25], was related to the band-gap shrinkage of the dot and/or barriers due to the Coulomb interaction between carriers [25, 26] band-gap renormalisation (BGR). The peak of the PL signal observed for energies below $1600 \mathrm{meV}$, is due to the luminescence of the GaAs substrate. 
Finally, similar sharp spectral features and no significant shift of the PL peak energy has been observed for $\mathrm{x}=0.20$ (sample A), were unambiguously proved to the high QD confinement.

The extract of the PL peak energy measurement for the studied samples was performed as a function of the excitation density at $10 \mathrm{~K}$, is shown in Fig. 6. For sample A $(\mathrm{x}=0.20)$, the PL energy seems to be independent of the excitation density with a value of $1674 \mathrm{meV}$, may attributed to the deepest confinement. Samples B $(\mathrm{x}=0.29)$ and $\mathrm{C}(\mathrm{x}=0.38)$ show a similar behavior, the PL peak energy decreases with increasing excitation density. The redshift is attribute to the decrease of the carrier diffusion between QDs due to the low QDs density.

We have also analyzed the FWHM of the QD PL spectra as a function of excitation density (see Fig. 7) at low temperature $(\mathrm{T}=10 \mathrm{~K})$. A significant difference can be seen for the samples. The FWHM keeps constant for $\mathrm{x}=0.20$ (black square), increases for $\mathrm{x}=0.29$ (green circles) and decreases for $\mathrm{x}=0.38$ (blue triangles) with increasing the aluminium proportion in the $\mathrm{In}_{1 \text { - }}$ ${ }_{\mathrm{x}} \mathrm{Al}_{\mathrm{x}} \mathrm{As}$ QDs. For sample C $(\mathrm{x}=0.38)$, the FWHM is reduced, due to the carriers escape from the smallest QDs (and in the confined states with the lowest confinement energy) to the WL. This leads to a decrease of the emission by small QDs, to a narrowing of the PL spectra on the high-energy side, and to reduction of the FWHM. Some articles [27, 28] informed that there are several approaches to obtain larger sized QDs such as the ultra-low-growth rate. Indeed, the band-gap renormalisation (BGR) can significantly modify the optical transitions [27] and especially in the larger sized QDs. The size, uniformity and density of InAlAs QDs can be controlled by varying the total flux of InAlAs and InAs [29]. For sample A $(x=0.20)$, the FWHM keeps constant with increasing excitation density, this is may be due to the further strong interaction between a larger population of e-h pairs in QDs since there is no loss of carriers by radiative recombination from GS. Finally, for sample B $(x=0.29)$, with increasing excitation density, most of the deepest QDs are concerned, the excitons are strongly localized, the PL spectra tend to the QD emission distribution [30], and the FWHM increases, as observed.

Fig. 8 shows the analysis of the integrated PL intensity (IPL) on excitation density of samples $\mathrm{A}(\mathrm{x}=0.20)$ (black squares), $\mathrm{B}(\mathrm{x}=0.29)$ (green circles) and $\mathrm{C}(\mathrm{x}=0.38)$ (blue triangles). The integrated PL intensity measurement is attributed to the emission from the GS QD samples. 
Remarkably, a saturation of the integrated PL is observable on sample $\mathrm{C}(\mathrm{x}=0.38)$, around power $150 \mu \mathrm{W}$; such a saturation also appears to exist on sample $\mathrm{B}(\mathrm{x}=0.29)$, at a slightly higher optical power, but no saturation at all is demonstrated on sample $A(x=0.20)$. We interpret these results by a high surface density of QDs in sample A $(x=0.20)$ and a lower QD density in sample $C(x=0.38)$, the one in sample $B(x=0.29)$ being intermediate.

Because the QDs were covered by a GaAlAs epilayer, we couldn't have AFM or TEM images.

In the absence of TEM and AFM images, this point of view can be sustained by the fact that the QD density is known to be very high when the deposited amount of alloy, of which the QDs are made, is near the critical thickness; for greater amounts of deposited alloy, the QDs coalesce and the QD density diminishes [2].

It should be noted that the radiative lifetime $\tau_{\text {rad }}$ on temperature dependence has been studied in order to permit the difference density on the QDs. The radiative lifetime $\tau_{\text {rad }}$ of the fundamental QD exciton has been measured on samples A $(x=0.20), B(x=0.29)$ and $C(x=$ 0.38 ), using a time-resolved photoluminescence (TRPL) experiment. The photoexcitation is performed by a picosecond pulsed laser beam, tuned at $425 \mathrm{~nm}$ (doubled $80-\mathrm{MHz}$ titaniumsapphire laser) and of typical mean power $5 \mu \mathrm{W}$; this beam is focused on the sample surface in a $1 \mu \mathrm{m}$-diameter spot. The sample is fixed on the cold finger of a variable-temperature helium-flow cryostat. The TRPL signals are recorded by a streak camera; the spectral bandwidth was about $0.5 \mathrm{meV}$; they show mono-exponential decays. In the selected spectral window, we measure the TRPL of QDs with a fixed size (and confinement energy).

Fig. 9 shows the temporal profiles of the PL signal at the peak energy, for different temperatures for the sample A $(x=0.20)$. The decay traces of Fig. 9 are single exponential $\left(I_{P L}=A_{1} \exp \left(-\frac{t}{\tau_{1}}\right)+A_{2}\right)$ over two orders of magnitude, and the observed decay times obtained by single exponential fits at different detection energies are summarized in Fig. 10. The corresponding characteristics times $\tau_{\text {rad }}$ are found in the nanosecond range. They are plotted in Fig. 10, for the three aforementioned samples, as a function of the temperature; the detection energy is chosen at the maximum of the PL signal. At low temperature in sample A $(\mathrm{x}=0.20)$, the exciton radiative lifetime is nearly constant, as one expects for confining QDs [31,32], owing to the nominally zero-dimensional (0D) character of the density of states [33]. 
For high QD density, a lateral coupling may lead to a 2D-regime with a linear excitation lifetime increase at high temperature. We have to correlate measurements of the exciton lifetime with measurements of the oscillator strength. Using Andreani and al [34] theory, the decay time $\tau_{0}=60 p s$ at $k_{\|}=0$ and the oscillator strength, which is on the same order of magnitude as those found in typical QWs. For the samples $B(x=0.29)$ and $C(x=0.38)$, one observed a nearly constant decay time, in agreement with the process moderate QD density [35].

\section{Conclusions}

We have studied the optical properties of self-assembled $\operatorname{In}_{1-\mathrm{x}} \mathrm{Al}_{\mathrm{x}} \mathrm{As}$ QDs system for different aluminium compositions. The density of InAlAs QDs decreases as the aluminium proportions increases from 0.20 to 0.38 . With increasing excitation power, the QD emission energy was red-shifted for the highest aluminium proportion, this behavior being attributed to the carrier trapping, while there is no significant shift for the lowest aluminium proportion, attributed to the high QD density. With increasing the aluminium proportion, our study shows a saturation, a decrease and an increase of the FWHM versus excitation density due to a larger population of e-h pairs in QDs, deepest QDs states and carrier transfer process respectively. 


\section{REFERENCES}

*Also at Paris-7 university, F-75013 Paris, France.
${ }^{*}$ Also at Paris-4 university, F-75005 Paris, France.

[1] K. Nishi, "Device Applications of Quantum Dots", in "Semiconductor Quantum Dots", ed. Y. Masumoto and T. Takagahara, Springer-Verlag, Berlin (2002).

[2] M. Kroutvar, Y. Ducommun, J.J. Finley, M. Bichler, G. Abstreiter, and A. Zrenner, Appl. Phys. Lett. 83 (2003) 443.

[3] J.L. Jimenez, L.R.C. Fonseca, D.J. Brady, J.P. Leburton, D.E. Wohlert, and K.Y. Cheng, Appl. Phys. Lett. 71 (1997) 3558.

[4] D. Loss and D.P. DiVincenzo, Phys. Rev. A. 57 (1998) 120.

[5] M. Chamarro, F.Bernardot, C.Testelin, J.Phys. Cond. Mat. 19 (2007) 445007.

[6] E. C. Le Ru, J. Fack, and R. Murray, Physical Review B. 67 (2003) 245318.

[7] A. Patané, A. Polimeni, PC. Main, M. Henini, L. Eaves, Appl Phys Lett. 75 (1999) 814.

[8] P. Dawson, O. Rubel, SD. Baranovskii, K. Pierz, Abd PT, E O. Gobel, Phys Rev B. 72 (2005) 235301.

[9] W. Yang, H. Lee, J. Johnson, P. C. Sercel and A. G. Norman, Phy. Rev. B. 61 (2000) 2784. [10] D. Bimberg, M. Grundmann, and N. N. Ledentsov, 'Quantum Dot Heterostructures ", John Wiley \& Sons Ltd, New York (1999).

[11] K. Lüdge, 'Modeling Quantum Dot based Laser Devices, in Nonlinear Laser Dynamics - From Quantum Dots to Cryptography”, edited by K. Lüdge, Wiley-VCH, Weinheim, 1 (2012) 3-34.

[12] E. U. Rafailov, M. A. Cataluna, and E. A. Avrutin, 'Ultrafast Lasers Based on Quantum Dot Structures"'Wiley-VCH, Weinheim (2011).

[13] A. Ben Daly, F. Bernardot, T. Barisien, A. Lemaître, M.A. Maaref, C. Testelin, Solid State Communications. 227 (2016) 9-12.

[14] A. Sahli, A. Melliti, M.A. Maaref, C. Testelin, A. Lemaître, R. Kuszelewicz, P. Voisin, Phys. Status Solidi (b). 244 (2007) 2622.

[15] X.M. Lu, Y. Izumi, M. Koyama, Y. Nakata, S. Adachi, S. Muto, J. Cryst. Growth 322 (2011) 6.

[16] R. Leon, S. Fafard, D. Leonard, J.L. Merz, P.M. Petroff, Appl. Phys. Lett. 67 (1995) 521.

[17] R. Passler, J. Appl. Phys. 88 (2000) 2570, and references therein.

[18] A. Ben Daly, F. Bernardot, T. Barisien, E. Galopin, A. Lemaître, M.A. Maaref, C. Testelin, J of lumin. 158 (2015) 136-141.

[19] L. Vina, S. Logothetidis, M. Cardona, Phys. Rev. B 30 (1984) 1979-1991. 
[20] (a) R. Carles, N. Saint-Cricq, J.B. Renucci, M.A. Renucci, A. Zwick, Phys. Rev. B 22 (1980) 4804; (b) Solid State Commun. , 59 (1986) 869.

[21] Z.Y. Xu, Z.D. Lu, X.P. Yang, Z.L. Yuan, B.Z. Zheng, J.Z. Xu, Phys. Rev. B 16 (1996) 54.

[22] K. Mukai, N. Ohtsuka, H. Shoji, M. Sugawara, Appl. Phys. Lett. 68 (1996) 3013.

[23] D.I. Lubyshev, P.P. Gonzalez-Borrero, E. Marega Jr., E. Petitprez, N. La Scala Jr., P. Basmaji, Appl. Phys. Lett. 68 (1996) 205.

[24] H. Lee, W. Yang, Peter C. Sercel, Phy. Rev. B 55 (1997) 9757.

[25] R. Heitz, F. Guffarth, I. Mukhametzhanov, A. Madhikar, D. Bimberg, Phys. Rev. B 62 (2000) 16881-16885.

[26] K. Matsuda, K. Ikeda, T. Saiki, Appl. Phys. Lett. 83 (2003) 2250.

[27] J. X. Chen, A. Markus, A. Fiore, U. Oesterle, R. P. Stanley, J. F. Carlin, R. Houdré, M. Ilegems, L. Lazzarini, L. Nasi, M. T. Todaro, E. Piscopiello, R. Cingolani, M. Catalano, J. Katcki, J. Ratajczak, J. Appl. Phys. 91 (2002) 6710-6716.

[28] P. B. Joyce, T. J. Krzyzewski, G. R. Bell, T. S. Jones, S. Malik, D. Childs, R. Murray, J Cryst Growth. 227 (2001) 1000-1004.

[29] Se. Ra. Kwon, Mee-Yi. Ryu, and Jin. Dong. Song, Applied Science and Convergence Technology 23 (2014) 387-391.

[30] F. Guffard, S. Rodt, A. Schliwa, K. P.otschke, D. Bimberg, Physica E 25 (2004) 261270.

[31] L. Vina, S. Logothetidis and M. Cardona, Phys. Rev. B 30 (1984) 1979.

[32] R. Carles, N. Saint-Cricq, J.B.Renucci, M. A. Renucci and A. Zwick, Phys. Rev. B. 22 (1980) 4804.

[33] H S. Lycett, C. Roberts and R. Murray, Appl. Phys. Lett. 69 (1996) 4087.

[34] L. C. Andreani, F. Tassone, F. Bassani, Solid State Commun. 77 (9) (1991) 641.

[35] T. V. Torchynska and A. Stintz, J. Appl. Phys. 108 (2010) 1. 


\section{CAPTIONS}

TABLE I. Main characteristics of the presented $\operatorname{In}_{1-\mathrm{x}} \mathrm{Al}_{\mathrm{x}} \mathrm{As} / \mathrm{Ga}_{0.67} \mathrm{Al}_{0.33} \mathrm{As}$ samples. $\mathrm{x}$ is the $\mathrm{Al}$ proportion in the deposited $\operatorname{In}_{1-\mathrm{x}} \mathrm{Al}_{\mathrm{x}} \mathrm{As}$ alloy; the temperatures of the depositions and the growth rates are mentioned; the growth turns from $2 \mathrm{D}$ to $3 \mathrm{D}$ at the critical thickness, as observed from the RHEED monitoring; the total amount of deposition is measured as an equivalent thickness.

FIG. 1. Structure of the studied samples. The amount of deposited $\operatorname{In}_{1-\mathrm{x}} \mathrm{Al}_{\mathrm{X}} \mathrm{As}$ alloy and the $\mathrm{Al}$ proportion $\mathrm{x}$ differ from sample to sample (see Table I).

FIG. 2. Critical thickness as a function of the $A l$ nominal proportion $x$ in the deposited $I n_{1-}$ ${ }_{x} A l_{x} A s$ alloy on $G a_{0.67} A l_{0.33} A s$. The dots are the experimental data; different symbols are for different temperatures of deposition (see Table I). The (parabolic) curve is only a guide for the eyes.

FIG. 3. GS PL peak energies measured at various temperatures for different aluminium proportion. (a) Sample A ( $x=0.20)$, (b) Sample B ( $x=0.29)$ and (c) Sample C ( $x=0.38)$. Symbols are the experimental data, and the lines are calculated using Bose-Einstein (dashed red line) law. 
FIG. 4. FWHM of the PL spectra of the studied QDs, as a function of temperature for sample A ( $\mathrm{x}=0.20)$ (black square), (b) Sample B $(\mathrm{x}=0.29)$ (green square) and (c) Sample C ( $=0.38)$ (blue triangle).

FIG. 5. 10K-PL spectra taken at different excitation densities. (a) Sample A ( $x=0.20)$, (b) Sample B ( $\mathrm{x}=0.29)$ and (c) Sample C ( $\mathrm{x}=0.38)$.

FIG. 6. The excitation density dependence of the PL peak energy of the fundamental transition of the studied samples at $\mathrm{T}=10 \mathrm{~K}$ : A $(\mathrm{x}=0.20)$ (black square), (b) Sample B $(\mathrm{x}=0.29)$ (green square) and (c) Sample $\mathrm{C}(\mathrm{x}=0.38)$ (blue triangle).

FIG. 7. Evolution of the FWHM as a function of the excitation density in the studied samples at $\mathrm{T}=10 \mathrm{~K}$ : A $(\mathrm{x}=0.20)$ (black square), (b) Sample B ( $\mathrm{x}=0.29)$ (green square) and (c) Sample C $(\mathrm{x}=0.38)$ (blue triangle).

FIG. 8. Log-log plot of the integrated PL versus the excitation power of the studied samples at $\mathrm{T}=10 \mathrm{~K}$.

FIG. 9. (Color online) Time evolution of the PL intensity at the peak energy for sample A $(\mathrm{x}=0.20)$, at temperatures $10 \mathrm{~K}$ (blue line), $40 \mathrm{~K}$ (black line), and $80 \mathrm{~K}$ (red line).

FIG. 10. Exciton lifetime $\tau_{\text {rad }}$ of the fundamental QD exciton in samples A $(x=0.20$, black squares $), B(x=0.29$, green circles $)$ and $C(x=0.38$, blue triangles $)$, as a function of the temperature. 


\begin{tabular}{|c|c|c|c|c|}
\hline $\mathbf{x}$ & $\begin{array}{c}\text { Temperature } \\
\left({ }^{\circ} \mathbf{C}\right)\end{array}$ & $\begin{array}{c}\text { Growth rate } \\
(\mathbf{M L} / \mathbf{s})\end{array}$ & $\begin{array}{c}\text { Critical } \\
\text { thickness (ML) }\end{array}$ & $\begin{array}{c}\text { Deposited } \\
\text { amount (ML) }\end{array}$ \\
$\mathbf{0 . 2 0}$ & 540 & 1.77 & 2.7 & 3.4 \\
$\mathbf{0 . 2 9}$ & 550 & 1.20 & 2.9 & 3.7 \\
$\mathbf{0 . 3 8}$ & 560 & 0.92 & 3.7 & 6.4 \\
\hline
\end{tabular}




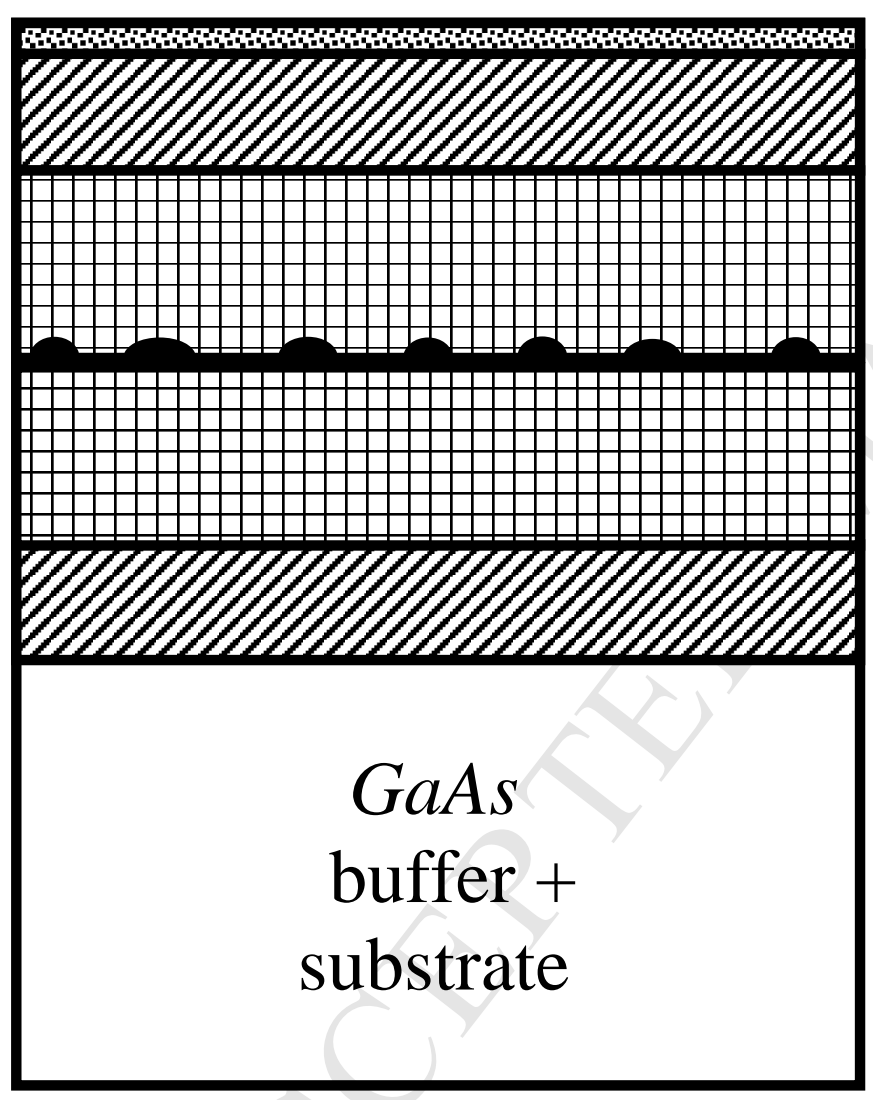

GaAs $5 \mathrm{~nm}$

$G a_{0.13} A l_{0.87} A s \quad 20 \mathrm{~nm}$

$G a_{0.67} A l_{0.33} A s \quad 100 \mathrm{~nm}$

$\operatorname{In}_{1-x} A l_{x} A s$

$G a_{0.67} A l_{0.33} A s \quad 100 \mathrm{~nm}$

$G a_{0.13} A l_{0.87} A s \quad 20 \mathrm{~nm}$ 


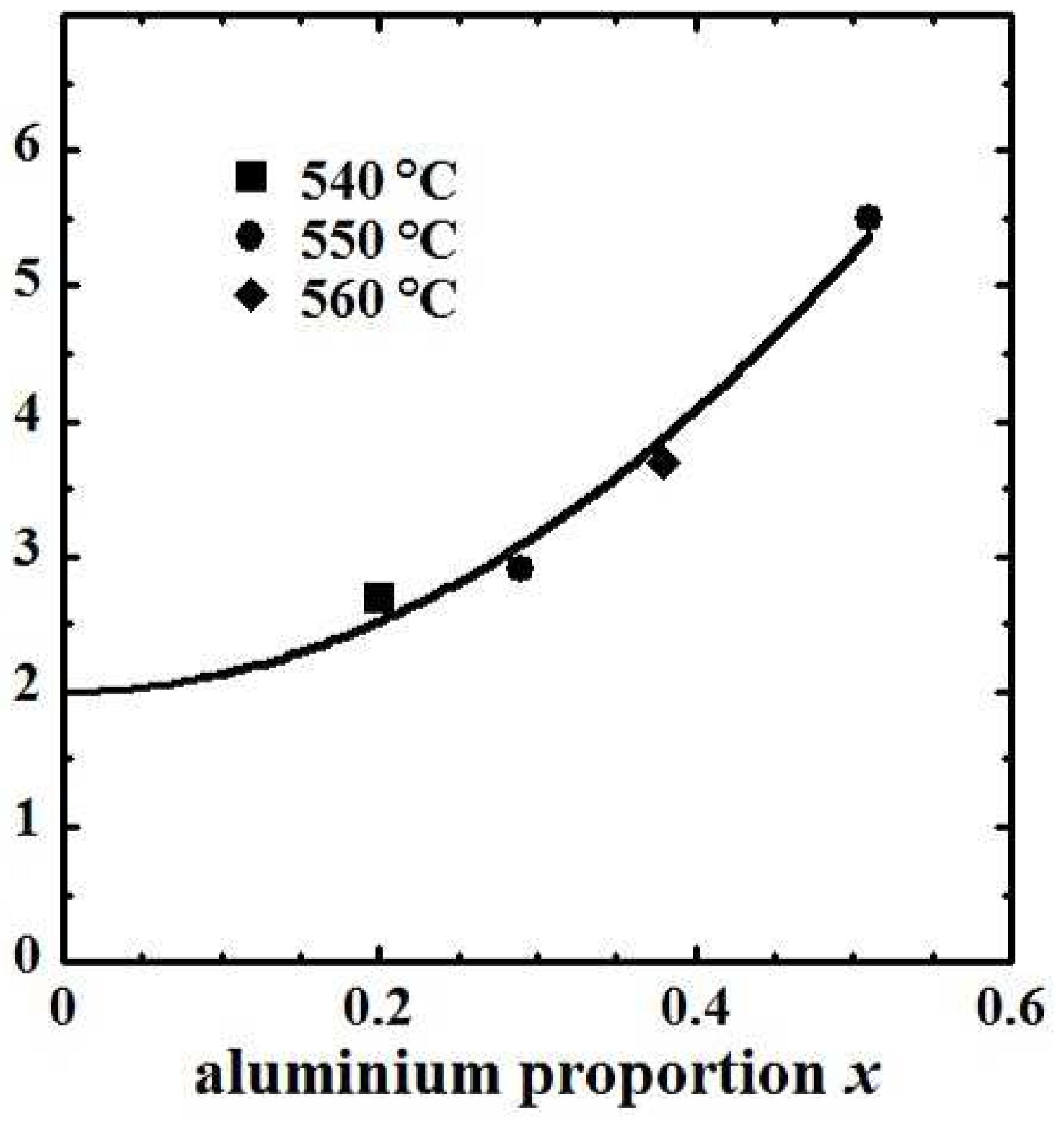




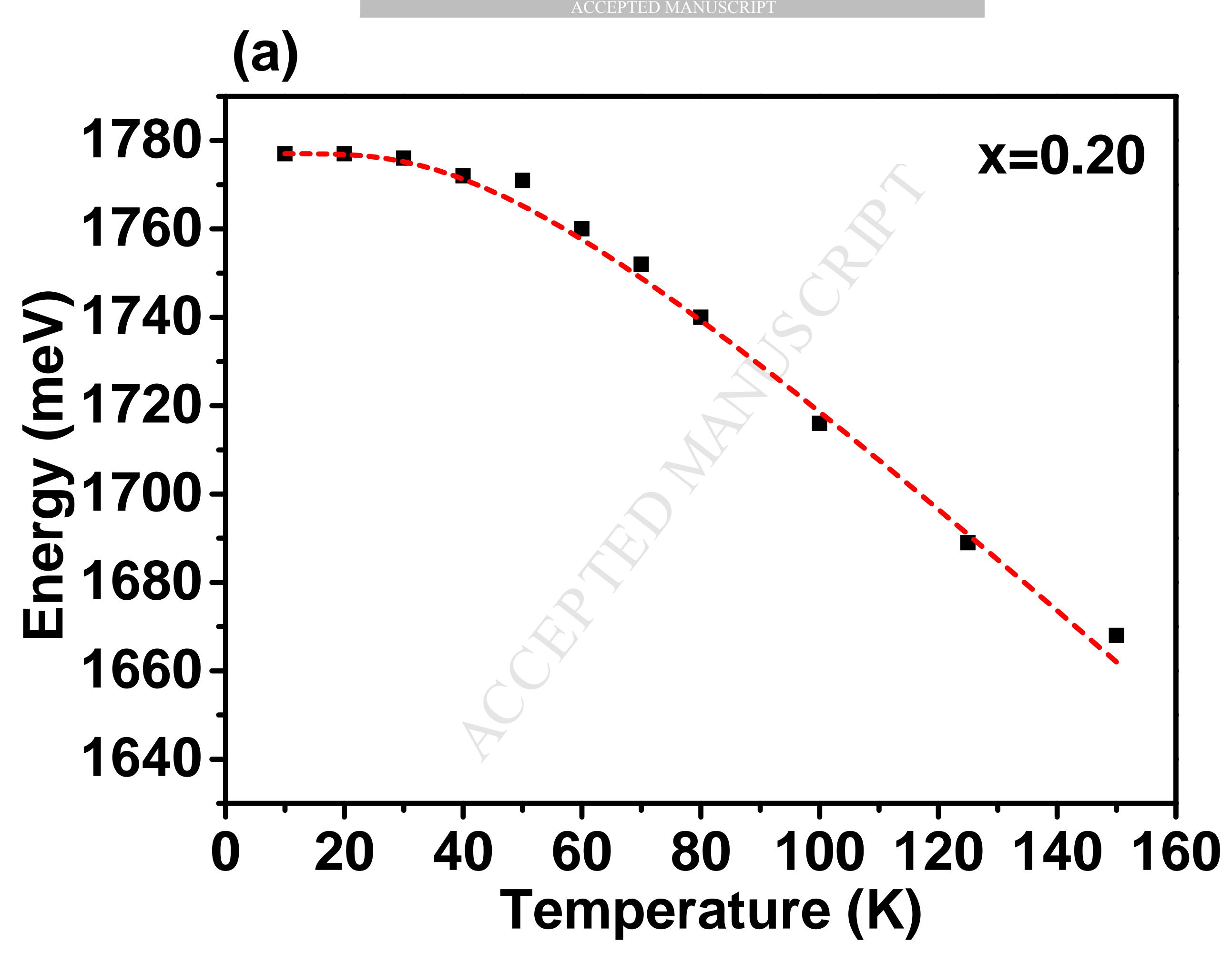




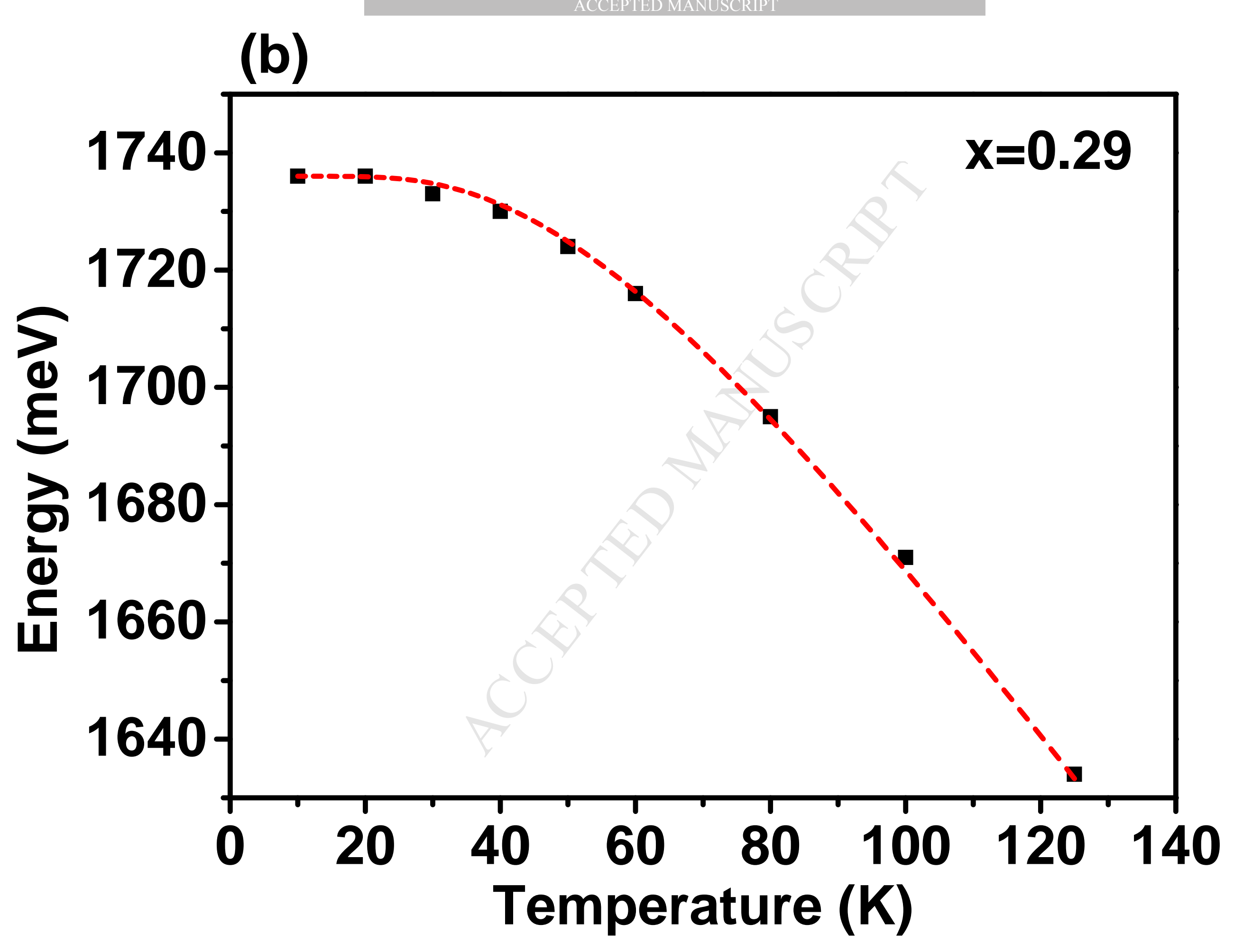




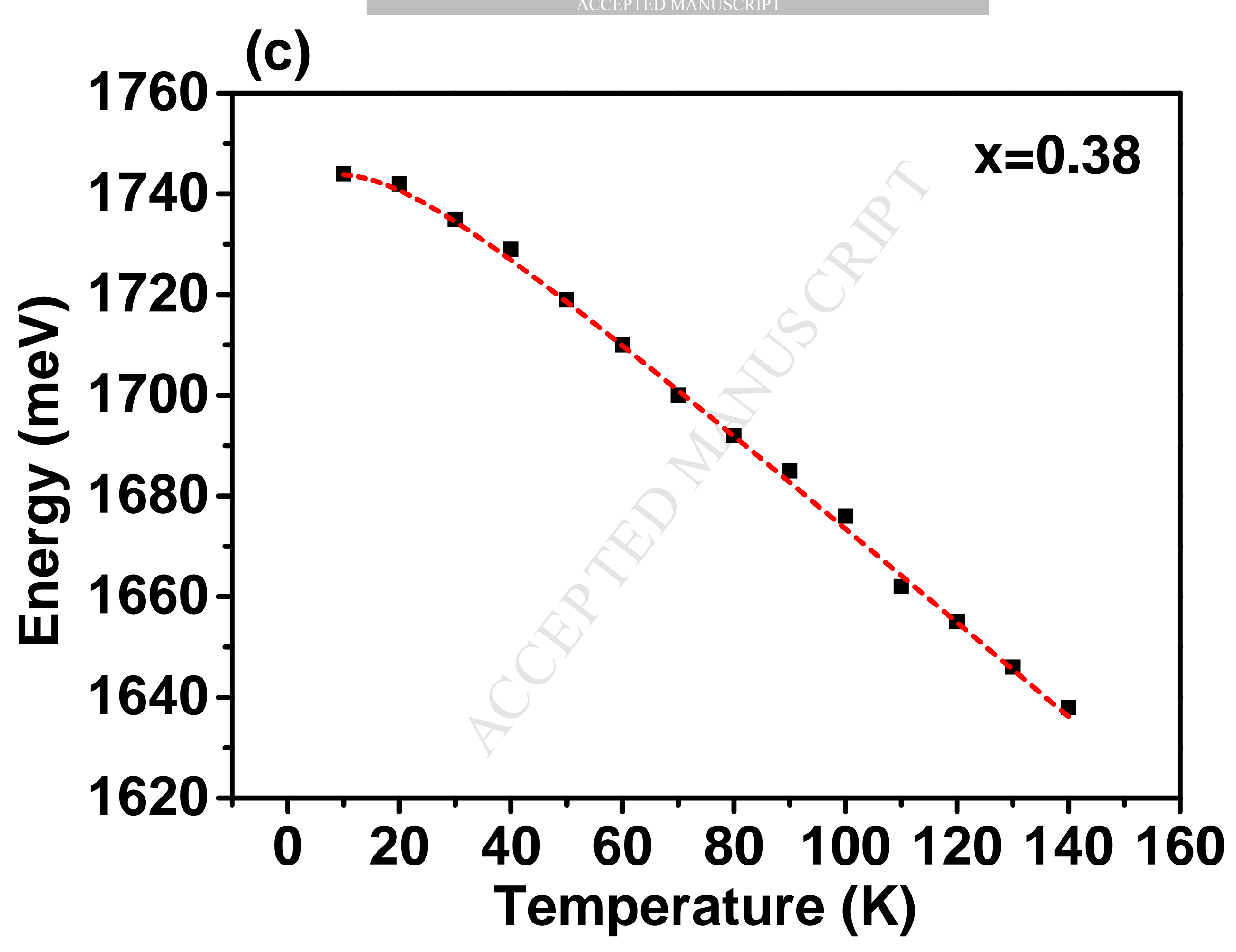




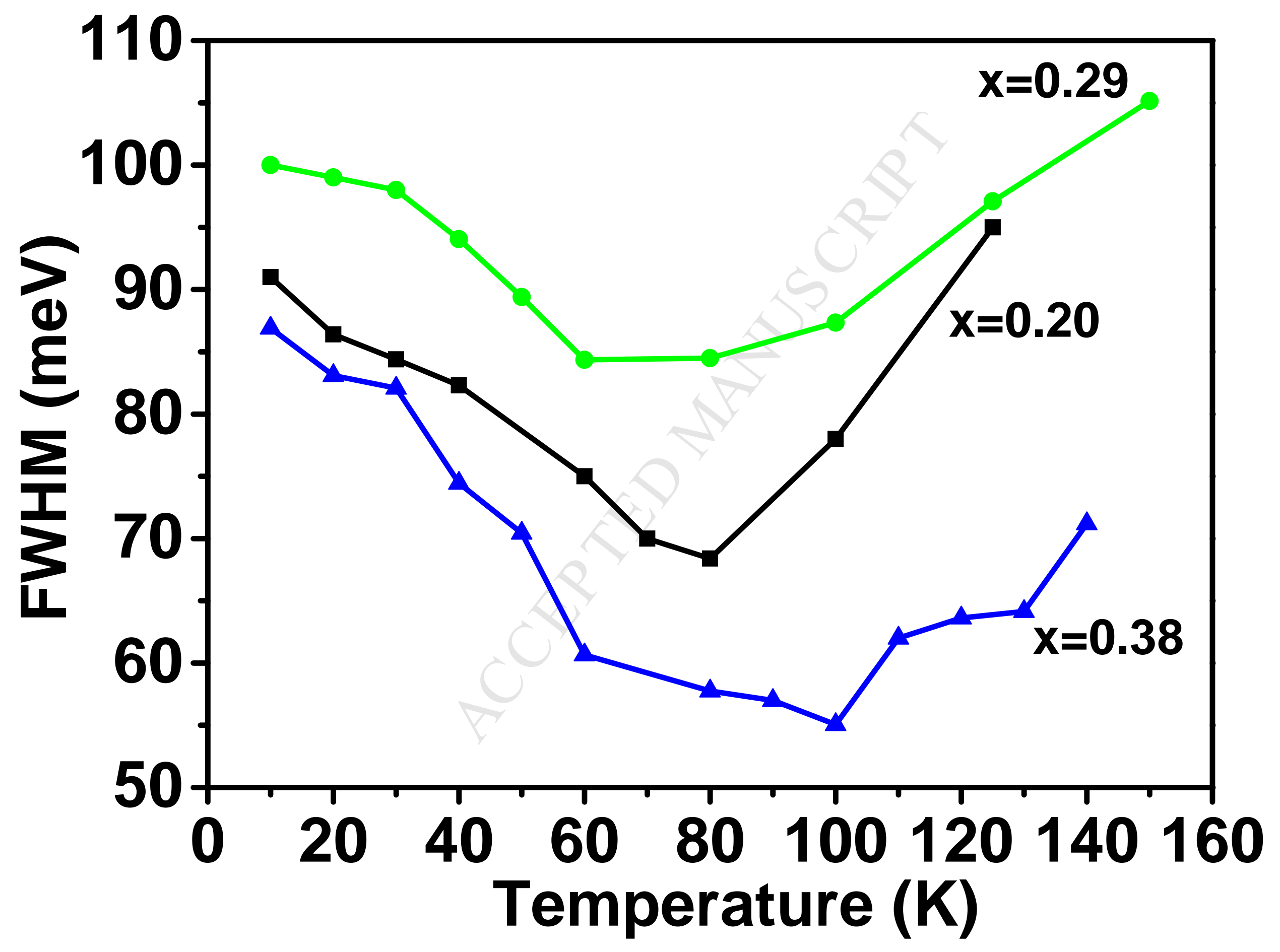




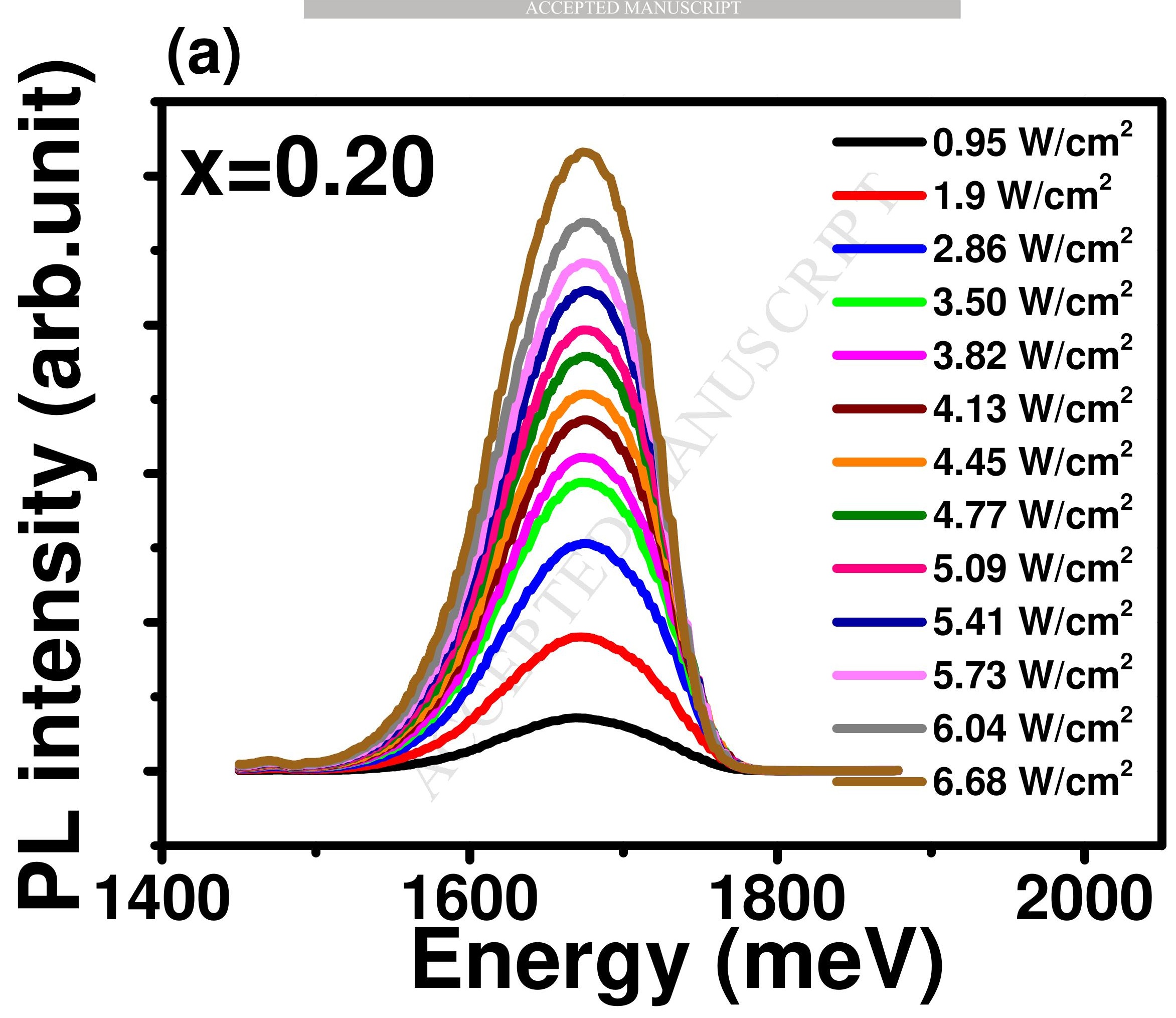




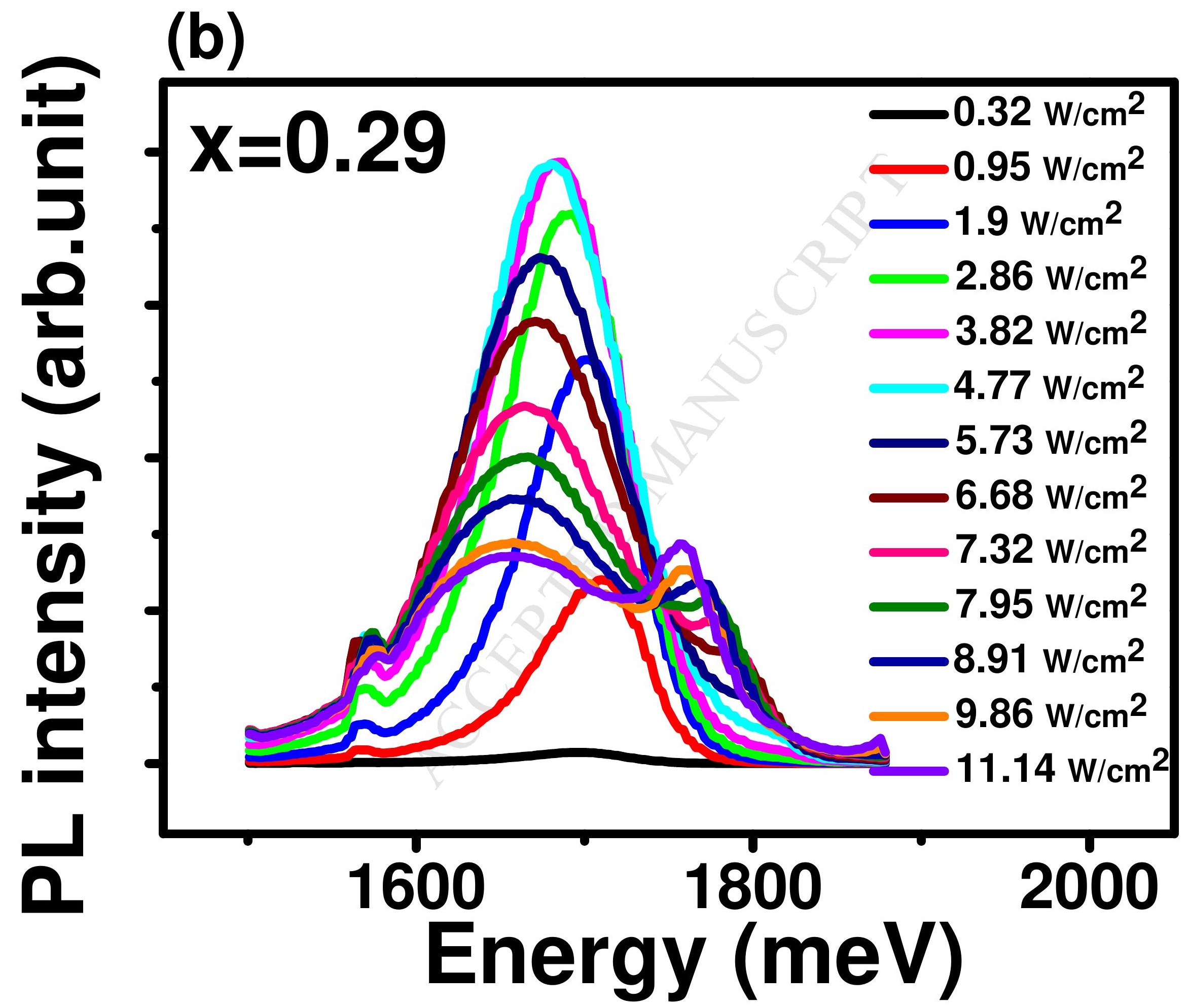




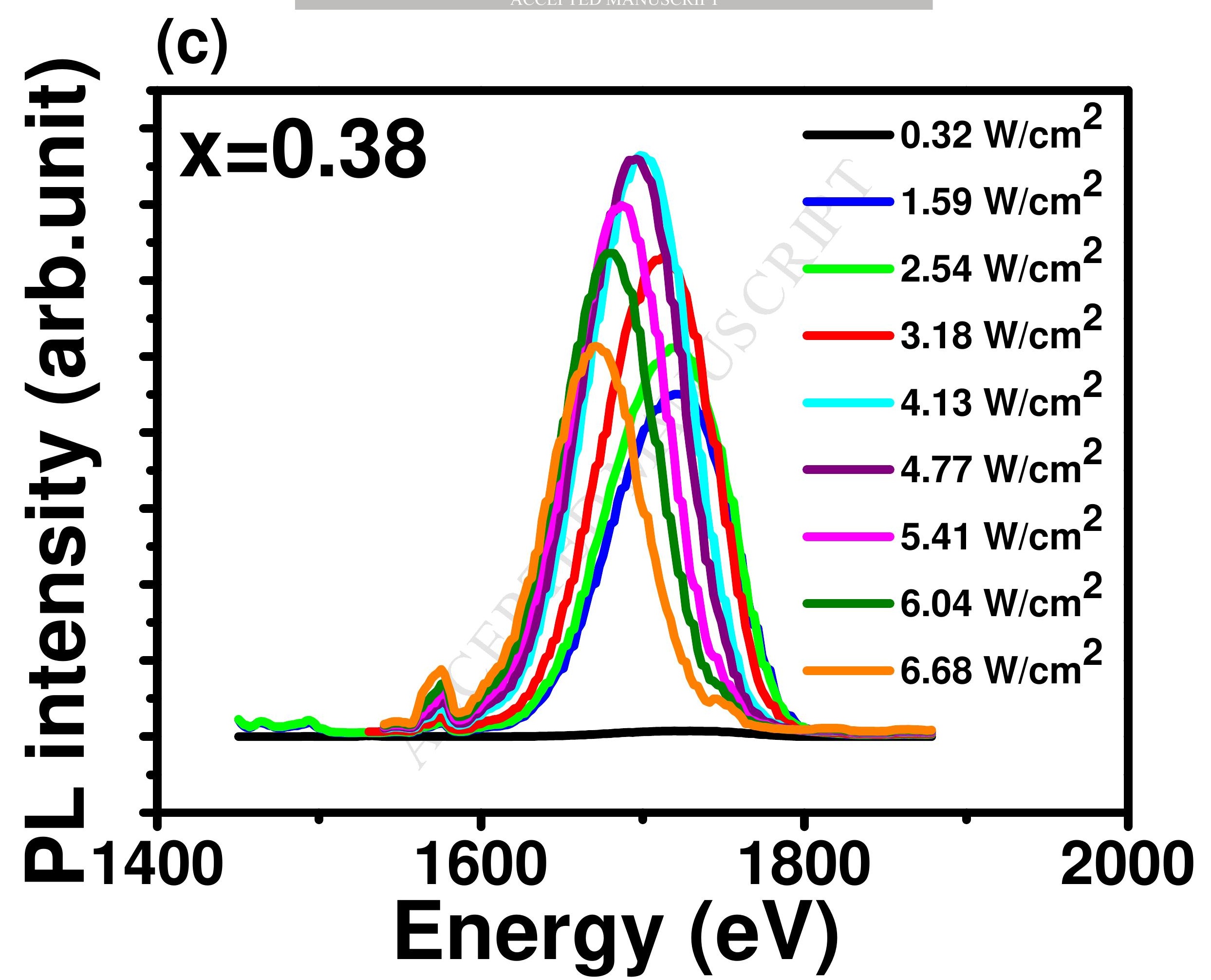




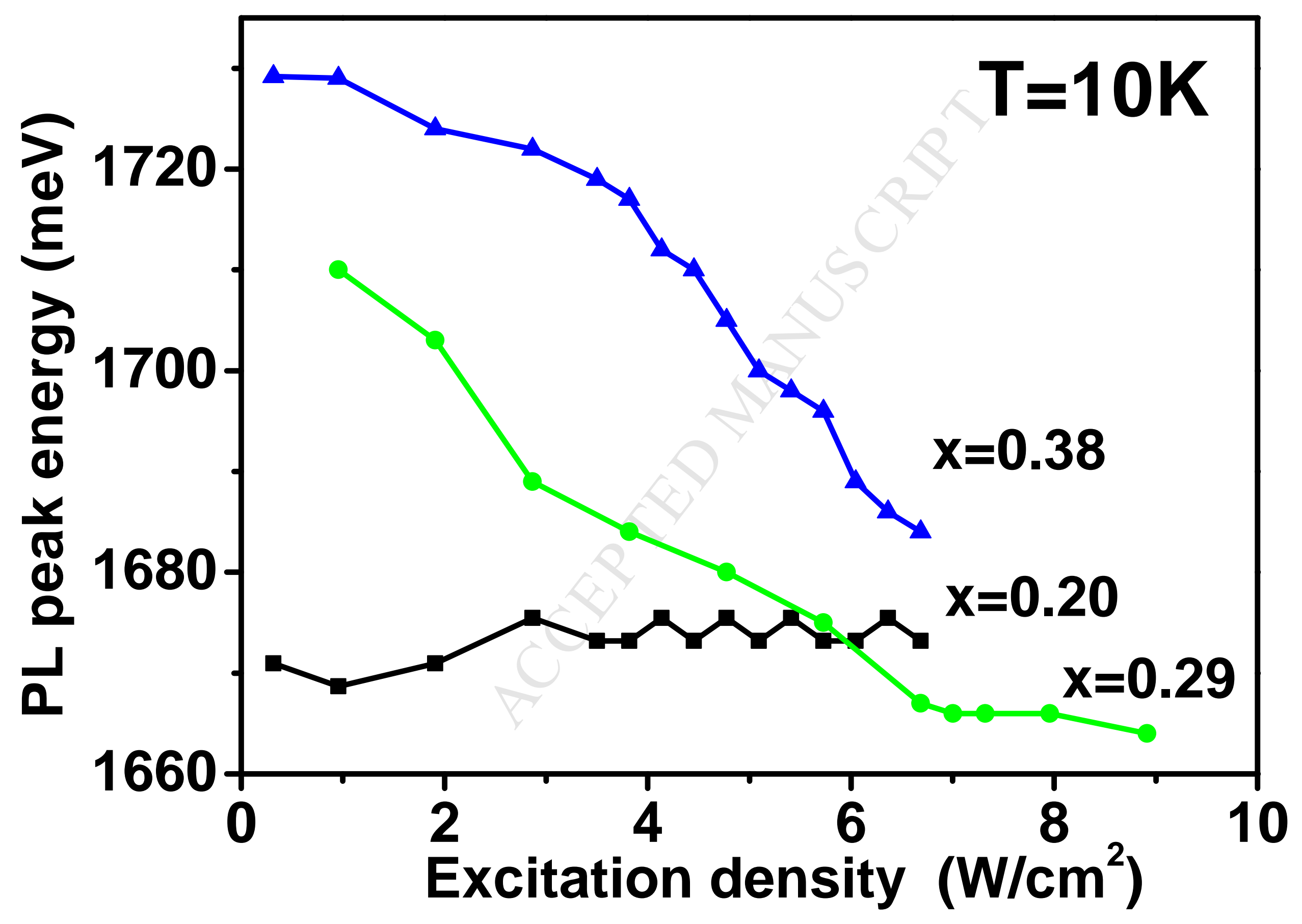




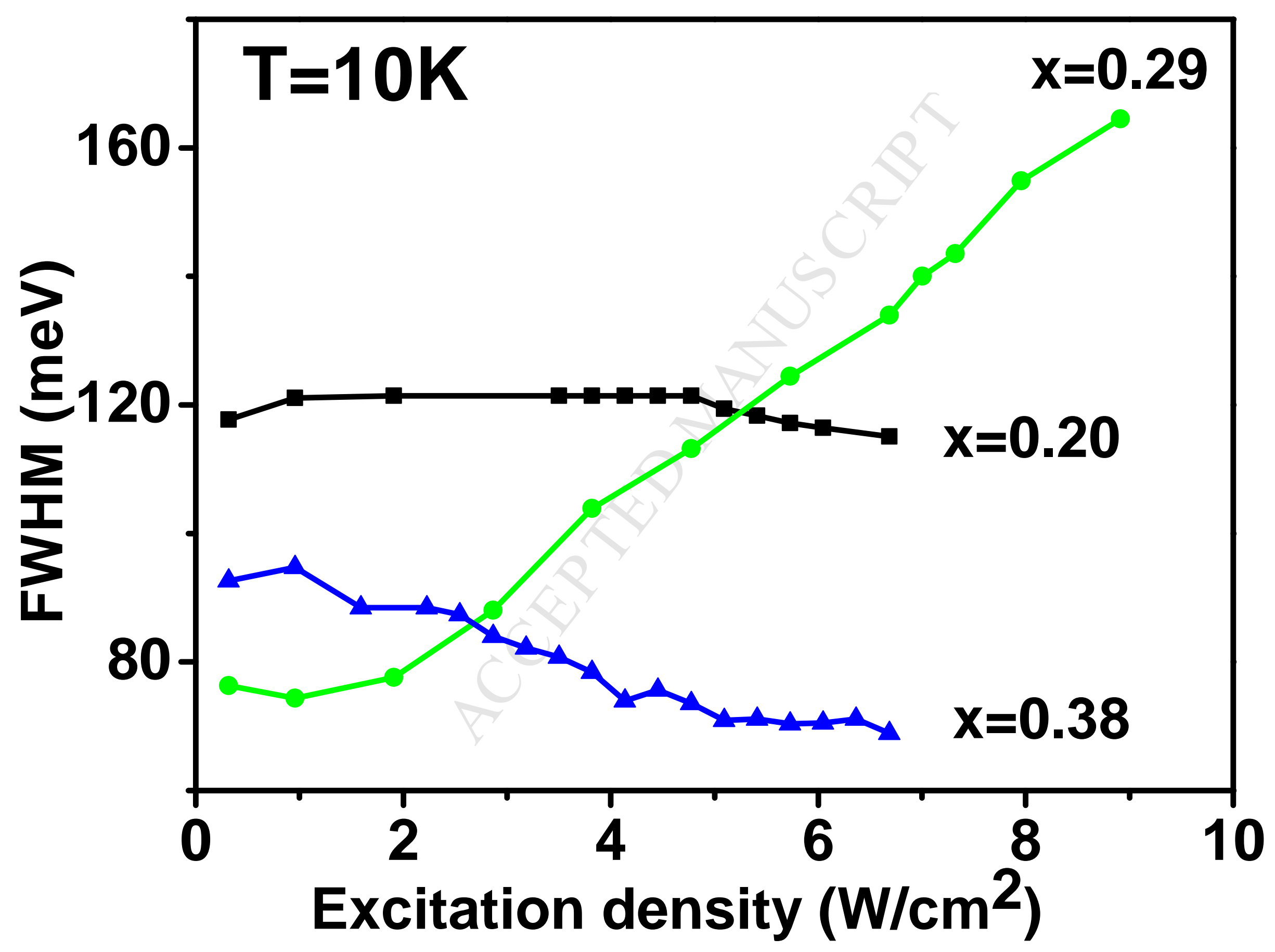




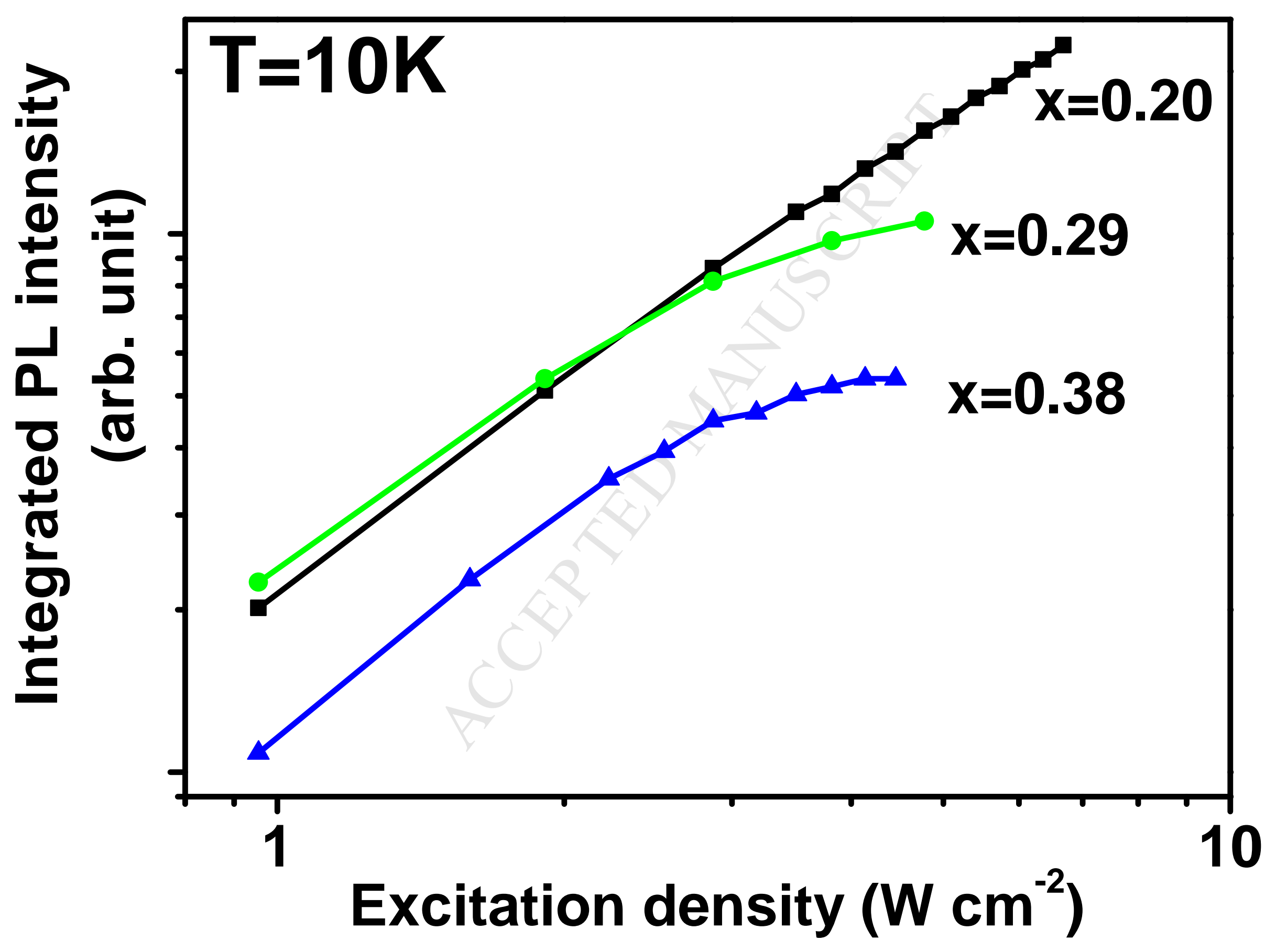




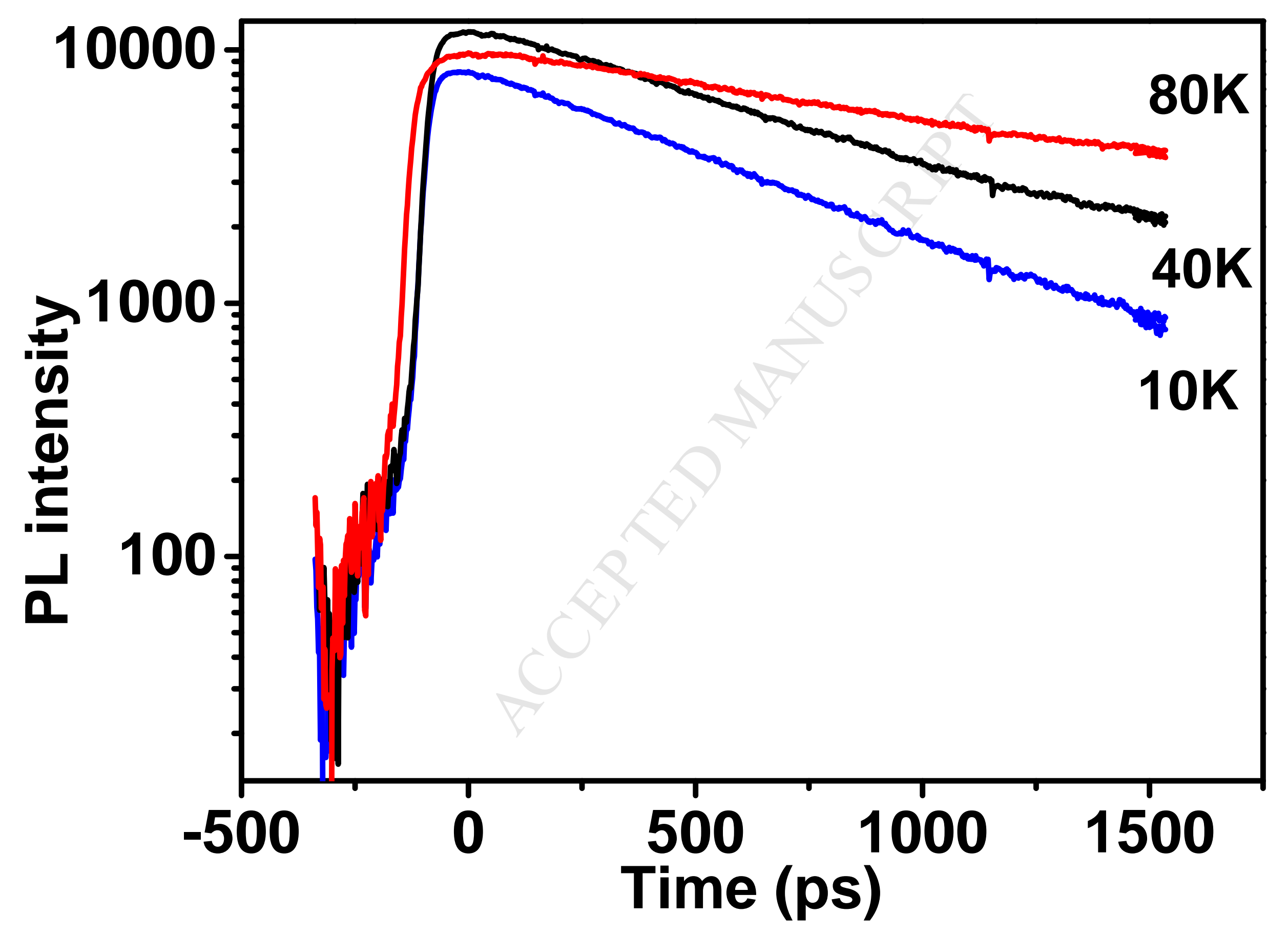




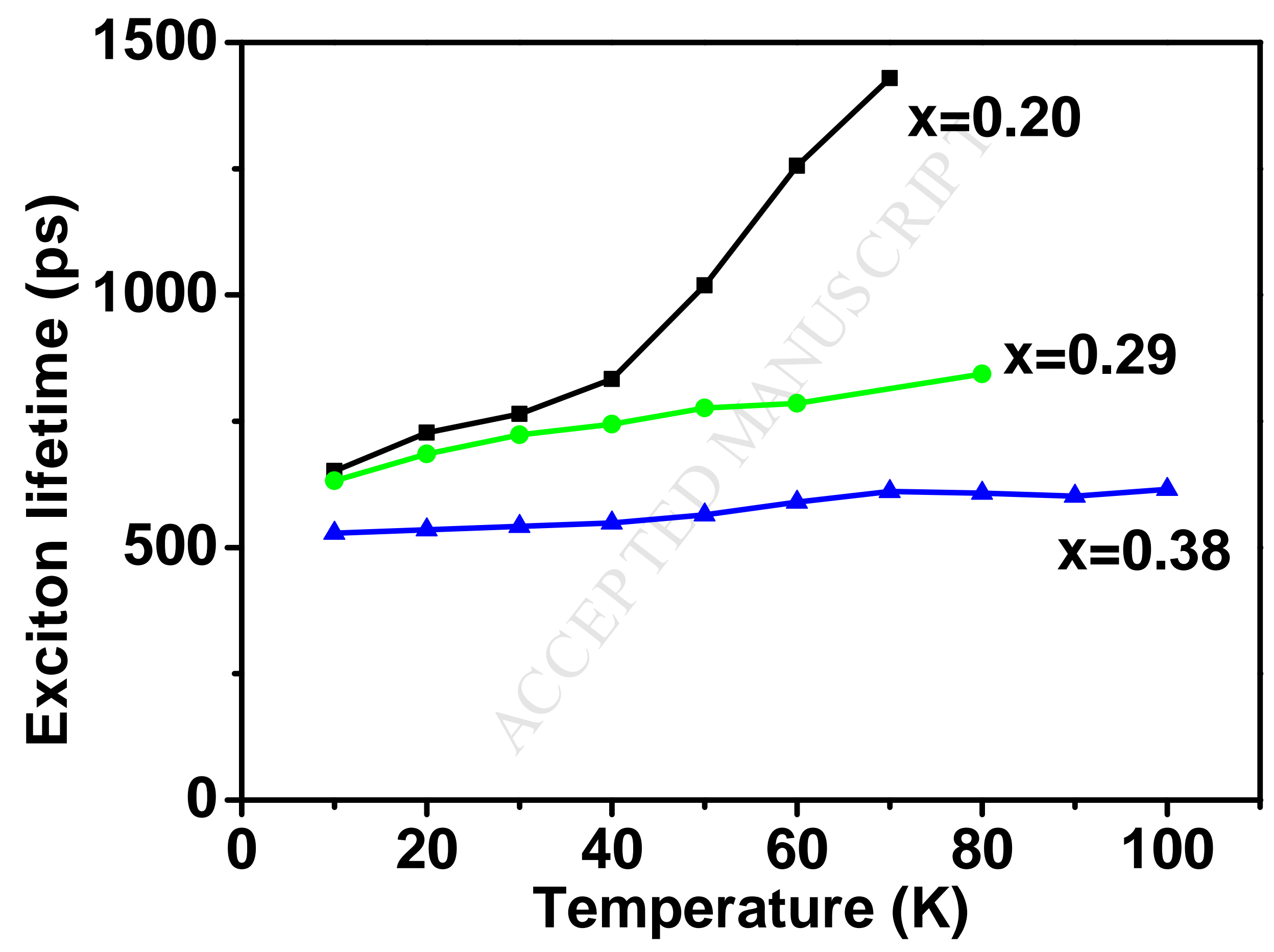




\section{Highlights}

* Photoluminescence (PL) and time-resolved photoluminescence (TRPL) studies have been performed on a visible-emitting InAlAs/GaAlAs quantum dot (QD) sample.

* The density of InAlAs QDs decreases as the aluminium proportions increases from 0.20 to 0.38 .

* In TRPL experiments, the influence of QD lateral coupling is evidence in high QD density sample.

* Signatures of the escape process are also evidenced in FWHM and emission energy dependence on excitation density. 